University of Nebraska - Lincoln

DigitalCommons@University of Nebraska - Lincoln

M. Eugene Rudd Publications

Research Papers in Physics and Astronomy

1965

New Autoionizing Levels in Helium

M. Eugene Rudd

University of Nebraska - Lincoln, erudd@unl.edu

Follow this and additional works at: https://digitalcommons.unl.edu/physicsrudd

Part of the Physics Commons

Rudd, M. Eugene, "New Autoionizing Levels in Helium" (1965). M. Eugene Rudd Publications. 65.

https://digitalcommons.unl.edu/physicsrudd/65

This Article is brought to you for free and open access by the Research Papers in Physics and Astronomy at DigitalCommons@University of Nebraska - Lincoln. It has been accepted for inclusion in M. Eugene Rudd Publications by an authorized administrator of DigitalCommons@University of Nebraska - Lincoln. 


\title{
New Autoionizing Levels in Helium
}

\author{
M. E. Rudd \\ Concordia College, Moorhead, Minnesota
}

Received 19 August 1965

We recently reported the excitation of autoionizing states in helium by positive-ion bombardment and their subsequent observation as fine structure in the energy spectrum of the emitted electrons. With somewhat increased resolution we have now observed additional levels in helium including parts of two series not previously reported.

Published in Physical Review Letters 15, 580 - 581 (1965)

(C)1965 The American Physical Society. Used by permission.

URL: http://link.aps.org/doi/10.1103/PhysRevLett.15.580

DOI: 10.1103/PhysRevLett.15.580 


\title{
NEW AUTOIONIZING LEVELS IN HELIUM*
}

\author{
M. E. Rudd
}

Concordia College, Moorhead, Minnesota

(Received 19 August 1965)

We recently reported the excitation of autoionizing states in helium by positive-ion bombardment and their subsequent observation as fine structure in the energy spectrum of the emitted electrons. ${ }^{1}$ With somewhat increased resolution we have now observed additional levels in helium including parts of two series not previously reported.

The same apparatus was used as in the previous work except for the addition of an $X-Y$ recorder to plot the data. Again, electrons ejected at a $160^{\circ}$ angle with respect to the ion beam were observed. The helium pressure in the collision chamber was five to six microns. The bombarding ions were $75-\mathrm{keV} \mathrm{H}^{+}$or $\mathrm{H}_{2}{ }^{+}$.

In Fig. 1 are shown three runs at different recorder sensitivities. The peak at $62.15 \mathrm{eV}$ can be identified as the $\left(2 p^{2}\right)^{1} S$ level calculated theoretically by O'Malley and Geltman ${ }^{2}$ but not previously observed. The peak at $63.65 \mathrm{eV}$ is the $s p, 23^{+}$level observed by Madden and Codling. ${ }^{3}$ The $64.46-\mathrm{eV} s p, 24^{+}$level is just detectable.

The energy scale could be determined by add-

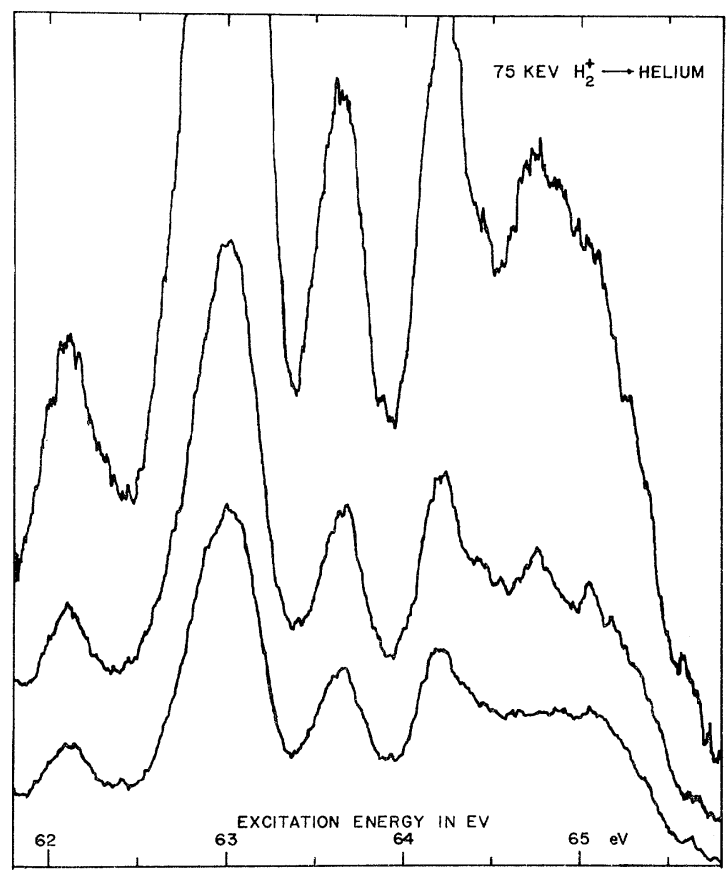

FIG. 1. Energy spectrum of electrons emitted from helium gas excited by $75-\mathrm{keV} \mathrm{H}_{2}{ }^{+}$impact. ing the ionization potential $(24.58 \mathrm{eV})$ to the electron ejection energy measured by the analyzer. However, because of space charge and other effects the energies thus determined are uncertain by a few tenths of an eV. Therefore, the $63.65-\mathrm{eV}$ value for the $s p, 23^{+}$level measured by Madden and Codling was used to calibrate the rest of the energy scale. The energies determined in this way are believed to be accurate to within about $0.05 \mathrm{eV}$.

The new series are the $(2 s n s)^{1} S$ and the $(2 s n p)$ ${ }^{3} P$, the first terms of which have been previously reported by Simpson, Mielczarek, and Cooper ${ }^{4}$ and by us. ${ }^{1}$ Both series converge to the same limit as the $s p, 2 n$ series. This limit is given by Madden and Codling ${ }^{3}$ as $65.397 \mathrm{eV}$. The $n=3$ terms in both series are combined in the single peak at $63.0 \mathrm{eV}$ in Fig. 1. In Fig. 2 these two levels have just been resolved at 62.95 and $63.08 \mathrm{eV}$. An additional peak appearing as $62.78 \mathrm{eV}$ is probably the $s p, 23^{-}$level reported by Madden and Codling. ${ }^{3}$ The $(2 s 4 s)^{1} S$ and $(2 s 4 p)^{3} P$ states appear as a single unresolved peak in Fig. 1 at $64.22 \mathrm{eV}$, while the peak at $64.71 \mathrm{eV}$ is probably the combination

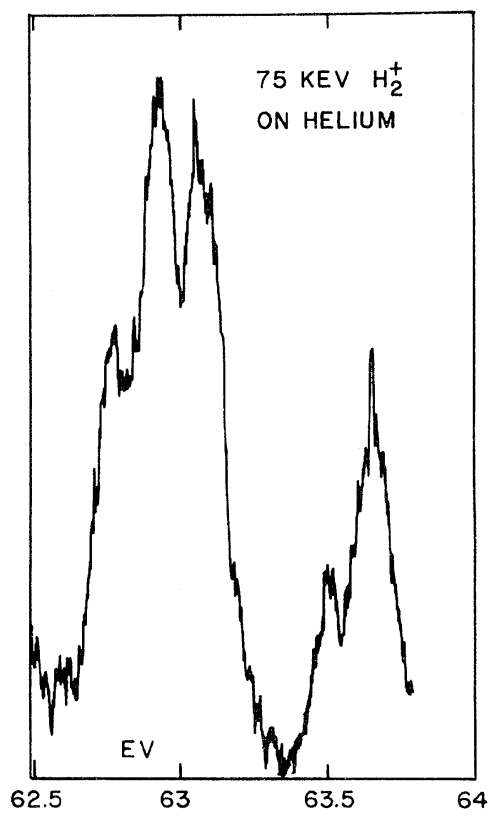

FIG. 2. Higher resolution energy spectrum of electrons emitted from helium gas excited by $75-\mathrm{keV} \mathrm{H}_{2}{ }^{+}$ impact. 
Table I. Energies of terms of $(2 s n s)^{1} S$ series in helium.

\begin{tabular}{cccc}
\hline \hline & $\begin{array}{c}E_{\text {expt. }} \\
(\mathrm{eV})\end{array}$ & $\begin{array}{c}E_{\text {calc }^{\mathrm{a}}} \\
(\mathrm{eV})\end{array}$ & $\begin{array}{c}E_{\text {calc }}^{\mathrm{b}} \\
(\mathrm{eV})\end{array}$ \\
\hline 2 & 57.82 & 57.87 & 57.824 \\
3 & 62.95 & 62.99 & 62.952 \\
4 & 64.22 & 64.22 & \\
5 & 64.71 & 64.70 & \\
\hline \hline
\end{tabular}

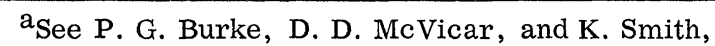
Phys. Rev. Letters 11, 559 (1963); P. G. Burke and D. D. McVicar, to be published.

${ }^{b}$ See reference 2 .

of the $n=5$ terms of both series. A summary of the measured and calculated values of the energies of the two series appears in Tables I and II.

Identification of the two series was aided by the fact that triplet levels are not excited by proton bombardment but show up strongly un$\operatorname{der} \mathrm{H}_{2}^{+}$bombardment. This is due to the fact that in order to conserve spin the triplet levels must be excited by a projectile bearing an electron to exchange with one in the target atom. With the proton beam the terms of the $(2 s n p){ }^{3} P$ series did not appear.
Table II. Energies of terms of the $(2 s n p)^{3} P$ series in helium.

\begin{tabular}{cccc}
\hline \hline & $\begin{array}{c}E_{\text {expt. }} \\
(\mathrm{eV})\end{array}$ & $\begin{array}{c}E_{\text {calc }^{\mathrm{a}}} \\
(\mathrm{eV})\end{array}$ & $\begin{array}{c}E_{\text {calc }^{\mathrm{b}}} \\
(\mathrm{eV})\end{array}$ \\
\hline 2 & 58.34 & 58.36 & 58.296 \\
3 & 63.08 & 63.14 & 63.141 \\
4 & 64.22 & 64.26 & 64.320 \\
5 & 64.71 & 64.71 & \\
\hline
\end{tabular}

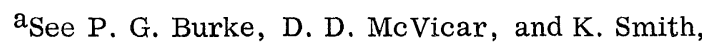
Phys. Rev. Letters 11, 559 (1963); P. G. Burke and D. D. McVicar, to be published.

$\mathrm{b}_{\text {See }}$ reference 2 .

We wish to express our gratitude to U. Fano and $\mathrm{C}$. Kuyatt for their helpful correspondence, and to D. Lang and D. Gregoire for assistance in taking the data.

*Work supported by the U. S. Atomic Energy Commission and the National Science Foundation.

${ }^{1}$ M. E. Rudd, Phys. Rev. Letters 13, 503 (1964).

${ }^{2}$ T. F. O'Malley and S. Geltman, Phys. Rev. $\underline{137}$, 1344 (1965).

${ }^{3}$ R. P. Madden and K. Codling, Astrophys. J. 141, 364 (1965).

${ }^{4}$ J. A. Simpson, S. R. Mielczarek, and J. Cooper, J. Opt. Soc. Am. 54, 269 (1964). 